\title{
PENGARUH BRISK WALKING EXERCISE TERHADAP TEKANAN DARAH PADA LANSIA
}

\author{
The Effect of Brisk Walking Exercise on Blood Pressure \\ Sonhaji*, Shindi Hapsari, Siti Nur Khusnul Khotimah \\ STIKES Karya Husada Semarang \\ (soni_aji84@yahoo.com / +62 857-4222-0298)
}

\begin{abstract}
ABSTRAK
Perubahan epidemiologi dimana terdapat penurunan penyakit menular dan peningkatan dalam penyakit tidak menular seperti hipertensi meningkat tiap tahunnya. Prevalensi kejadian hipertensi di seluruh dunia sekitar 972 juta orang atau 26,4\% masyarakat dunia mengalami hipertensi. Di Jawa Tengah pendudukan dengan usia $>20$ mengalami hipertensi dari 36,53\% dari 1.153.371 jumlah penduduk. Penelitian ini mengetahui Pengaruh Brisk Walking Exercise Terhadap Tekanan Darah Pada Lansia Di Rumah Pelayanan Sosial Lanjut Usia Puncang Gading Semarang dengan teknik sampling yaitu purposive sampling, Populasi dari penelitian ini sebanyak 29 sampel perlakuan dengan intervensi menggunakan latihan Brisk Walking Exercise dengan pengukuran tekanan darah menggunakan sfigmomanometer kemudian dianalisa untuk mengetahui pengaruh latihan terhadap tekanan darah. Berdasarkan analisa dengan menggunakan Uji Wilcoxon didapatkan $p$ value bernilai $0,000(<0,05)$, terdapat perubahan tekanan darah sebelum dilakukan dan sesudah dilakukan tindakan Brish Walking Execise. Frekuensi tekanan darah sebelum Brish Walking Exercise rata-rata pada 161,21 / 11,312 mmHg. Frekuensi tekanan darah sesudah Brish Walking Exercise rata-rata pada 140,34 / 8,010 mmHg. Ada perbedaan tekanan darah sebelum dan sesudah Brish Walking Exercise dengan p-value 0,000. Hasil penelitian ini dapat bermanfaat untuk penanganan lansia yang mengalami hipertensi, dengan cara memberikan Latihan Brisk Walking Exercise sehingga mampu mengurangi ketergantungan terhadap obat.
\end{abstract}

Kata Kunci :Brisk Walking Exercise, Tekanan Darah, Lansia

\section{ABSTRACT}

Epidemiological changes are a reduction in infectious diseases and an increase in noncommunicable diseases such as hypertension increases every year. The prevalence of hypertension around the world around 972 million people or $26.4 \%$ of the world community is increasingly hypertensive. In Central Java the occupation age $>20$ raised hypertension from $36.53 \%$ of the 1,153,371 population. This study studied the Effect of Fast Walking Exercise on Blood Pressure in the Elderly at Puncang Gading Semarang Elderly Social Services House with a sampling technique as purposive sampling. The population of this study amounted to 29 research samples using Rapid Running Exercise exercises using blood using a sphygmomanometer then analyzed to study the effect of exercise on blood pressure. Based on the analysis using the Wilcoxon Test, the p value is 0,000 (<0.05), pressure changes are carried out before it is done and after the Brish Walking Execise. The frequency of blood pressure before the Brish Walk Exercise averaged at $161.21 / 11.312 \mathrm{mmHg}$. The frequency of slow blood pressure Exercise Brish Walk averages at 140.34 / $8010 \mathrm{mmHg}$. There is a difference in blood pressure before and after the Brish Walking Exercise with a p-value of 0,000 . The results of this study can be useful for the treatment of the elderly who increase hypertension, by providing Exercise Fast Walking so as to reduce dependence on drugs.

Keywords: Brisk Walking Exercise, Blood Pressure, Elderly 


\section{PENDAHULUAN}

Sistem kesehatan Indonesia terjadi perubahan epidemiologi dimana terdapat penurunan penyakit menular dan peningkatan dalam penyakit tidak menular salah satunya yaitu hipertensi. Prevalensi hipertensi di Indonesia pada penduduk umur 18 tahun ke atas tahun 2007 di Indonesia adalah sebesar 31,7, Sedangkan jika dibandingkan dengan tahun 2013 terjadi penurunan sebesar 5,9\% (dari $31,7 \%$ menjadi 25,8\%). Penurunan ini bisa terjadi berbagai macam faktor, seperti alat pengukur tensi yang berbeda, masyarakat yang sudah mulai sadar akan bahaya penyakit hipertensi. Data Profil Kesehatan Jawa Tengah menunjukkan bahwa sebanyak $36,53 \%$ dari 1.153.371 penduduk Jawa Tengah yang berusia >20 tahun menderita hipertensi. Berdasarkan jenis kelamin pesentase hipertensi pada kelompok perempuan sebesar $13.10 \%$, lebih rendah dibanding pada kelompok laki-laki yaitu 13.16\%(DEPKES, 2013)

Terdapat dua pengobatan untuk menurunkan hipertensi, yaitu, farmakologi dan non farmakologi. Terapi farmakologi merupakan terapi menggunakan obat atau senyawa yang dapat mempengaruhi tekanan darah pasien. Terapi non farmakologi merupakan terapi tanpa menggunakan obat. Salah satu contoh terapi non farmakologi yaitu dengan membuat keadaan rileks, bergaya hidup sehat dan beraktivitas olahraga.(Afriwardi, 2009)

Menurut the American College of Sports Medicine, olahraga atau aktivitas fisik dengan intensitas sedang, seperti berjalan cepat dapat menurunkan mortalitas penderita gangguan kardiovaskular seperti hipertensi. Brisk Walking Exercise merupakan salah satu bentuk latihan aerobik dengan bentuk latihan aktivitas sedang pada pasien hipertensi dengan teknik jalan cepat(Niederhoffer KG, 2009). Brisk Walking Exercise ini cukup efektif untuk merangsang kontraksi otot, meningkatkan kapasitas denyut jantung, memecahkan glikogen serta peningkatan oksigen di dalam jaringan, selain itu latihan ini juga dapat mengurangi pembentukan plak melalui peningkatan penggunaan lemak dan peningkatan penggunaan glukosa.(Lipsky et al., 2008)

Brisk Walking Exercise bekerja melalui melalui penurunan resistensi perifer, pada saat otot berkontraksi melalui aktifitas fisik akan terjadi peningkatan aliran darah 30 kali lipat ketika kontraksi dilakukan secara ritmik(Marlia, 2010). Adanya dilatasi sfinter prekapiler dan arteriol menyebabkan peningkatan pembukaan 10-100 kali lipat pada kapiler. Dilatasi pembuluh darah juga akan mengakibatkan penurunan jarak antara darah dan sel aktif serta jarak tempuh difusi O2 serta zat metabolik sangat berkurang yang dapat meningkatkan fungsi sel karena 
ketercukupan suplai darah, oksigen serta nutrisi dalam sel. (Sonhaji and Lekatompessy, 2019)

Berdasarkan hasil survey bahwa kegiatan dengan brisk walking exercise di Rumah Pelayanan Sosial Lanjut Usia belum optimal dilaksanakan sehingga dalam penelitian ini bertujuan untuk mengetahui adanya pengaruh terhadap penurunan tekanan darah pada lansia.

\section{METODE}

Metode Penelitian ini menggunakan desain penelitian Quasi Experimen dengan rancangan pre-test tanpa menggunakan kelompok kontrol.(Notoadmojo, 2011) Tempat penelitian dilakukan di Rumah Pelayanan Sosial Lanjut Usia Pucang Gading Semarang pada bulan oktober - Desember 2019. Sampel pada penelitian ini dihitung dengan rumus Lemeshow sebanyak 29 responden dari kriteria inklusi diantaranya Lansia dengan tekanan darah lebih dari 140/90 mmHg, lansia yang mampu ADL Mandiri kemudian memberikan penjelasan tujuan penelitian. Setelah mendapatkan persetujuan dari responden dengan pengisian lembar informed consent, kemudian responden dilakukan pengukuran tekanan darah menggunakan sphygmomanometer 5 menit sebelum dilakukan latihan Brisk Walking. Latihan brisk Walking Exercise ini dilakukan selama 15-30 menit dipagi hari selama 1 minggu.

\section{HASIL}

\section{Analisis Univariat}

a. Tekanan darah sebelum Brisk Walking Excercise

Tabel 1. Distribusi frekuensi tekanan darah sebelumBrisk Walking Exercise di Rumah Pelayanan Sosial Pucang Gading Semarang

\begin{tabular}{cccccc}
\hline Variabel & $\mathrm{N}$ & Mean & Min & Max & Std \\
\hline Sistole & 29 & 161,21 & 150 & 180 & $\begin{array}{c}11,31 \\
2\end{array}$ \\
\hline Diastole & 29 & 105,69 & 100 & 120 & 7,036 \\
\hline
\end{tabular}

Hasil penelitian pada tabel 1 menunjukan bahwa distribusi frekuensi tekanan darah sistole sebelum perlakuan Brisk Walking Exerciserata-rata pada tekanan $161,21 \mathrm{mmHg}$, standar deviasi 11,312 $\mathrm{mmHg}$, dengan tekanan darah terendah $150 \mathrm{mmHg}$ dan tertinggi $180 \mathrm{mmHg}$. Distribusi frekuensi tekanan darah diastole sebelum perlakuanBrisk Walking Exercise rata-rata pada tekanan 105,69 $\mathrm{mmHg}$, standar deviasi 7,036 $\mathrm{mmHg}$ dengan tekanan darah terendah $100 \mathrm{mmHg}$ dan tertinggi $120 \mathrm{mmHg}$.

b. Tekanan darah sesudah Brisk Walking Exercise

Tabel 2. Distribusi frekuensi tekanan darah sesudah Brisk Walking Exercise di Rumah Pelayanan Sosial Pucang Gading Semarang

\begin{tabular}{cccccc}
\hline Variabel & N & Mean & Min & Max & $\begin{array}{c}\text { Std. } \\
\text { Deviatio } \\
\mathrm{n}\end{array}$ \\
\hline Sistole & 29 & 140,34 & 130 & 160 & 8,010 \\
\hline Diastole & 29 & 86,21 & 80 & 100 & 6,073 \\
\hline
\end{tabular}

Hasil penelitian pada tabel 2 menunjukan bahwa distribusi frekuensi tekanan darah 
sistole sesudah perlakuan Brisk Walking Exercise rata-rata pada tekanan 140,34 $\mathrm{mmHg}$, standar deviasi $8,010 \mathrm{mmHg}$, dengan tekanan darah terendah $130 \mathrm{mmHg}$ dan tertinggi $160 \mathrm{mmHg}$. Distribusi frekuensi tekanan darah diastole sebelum perlakuan Brisk Walking Exercise rata-rata pada tekanan $86,21 \mathrm{mmHg}$, standar deviasi $6,073 \mathrm{mmHg}$, dengan tekanan darah terendah $80 \mathrm{mmHg}$ dan tertinggi $100 \mathrm{mmHg}$.

\section{Analisa Bivariat}

a. Perbedaan tekanan darah sebelum dan sesudah Brisk Walking Exercise.

Dari hasil analisis normalitas data diketahui bahwa pada variabel tekanan darah sistole dan diastole sebelum dan sesudah Brisk Walking Exercise memiliki distribusi data yang tidak normal dengan p-value $<0,05$, sehingga dalam pemilihan uji beda dua variabel berhubungan yang berdistribusi tidak normal adalah uji wilcoxon.

Tabel 3. uji wilcoxon perbedaan tekanan darah sebelum dan sesudah Brisk Walking Exercise di Rumah Pelayanan Sosial Pucang Gading Semarang

Berdasarkan analisa bivariate dengan menggunakan Uji Wilcoxon didapatkan $p$ value bernilai $0,000(<0,05)$, maka dapat disimpulkan bahwa terdapat perubahan tekanan darah sebelum dilakukan dan sesudah di lakukan tindakan Brisk Walking Execise. Hal ini berarti Ho ditolak Ha di terima, dengan demikian dapat disimpulkan ada perbedaan sebelum dan sesudah dilakukan Brisk Walking Execise.Terhadap perubahan tekanan darah pada Lansia Rumah Pelayanan Sosial Pucang Gading Semarang.

\section{PEMBAHASAN}

Brisk walking exercise sebagai salah satu bentuk latihan aerobik bentuk moderate exercise pada lansia mengalami hipertensi dengan menggunakan tehnik jalan cepat selama 15-30 menit.(Rofacky and Aini, 2015) Pada lansia sebelum dilakukan Brish Walking Exercise terjadi peningkatan tekanan darah karena pada umumnya lansia memiliki riwayat hipertensi, peningkatan tekanan darah responden, bisa jadi karena lansia disana tidak terlalu banyak mengalami gerak hanya senam

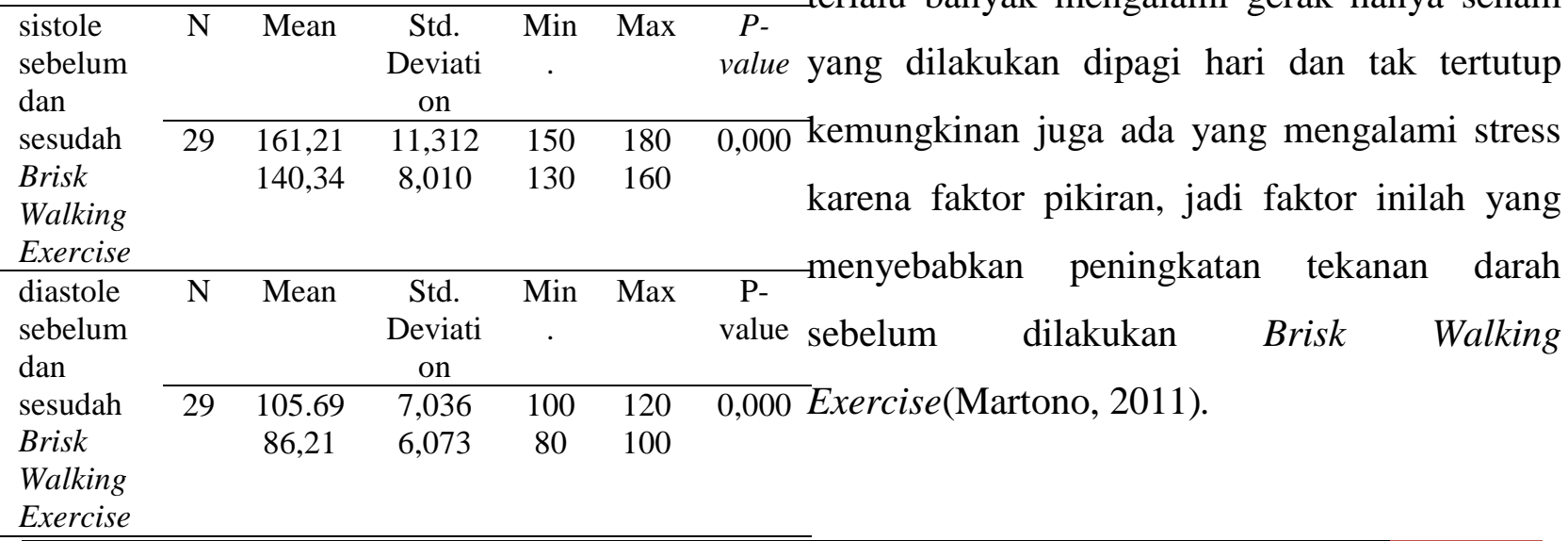


Lama waktu pemberian juga memiliki pengaruh dalam penurunan tekanan darah, dalam penelitian miyashita, selama 30 menit melakukan brisk walking exercise ini mampu efektif dalam mengurangi lipemia postprandial dan tekanan darah sistolik yang dilakukannya pada responden berjenis kelamin laki laki. Begitu halnya dalam penelitian ini, penurunan tekanan darah yang terjadi pada responden menunjukkan bahwa brisk walking exercise ini mampu menurunkan tekanan darah.(Miyashita, Burns and Stensel, 2008)

Pada studi penelitian lainnya bahwa, penuaan menyebabkan penurunan aktivitas fisik, fungsi organ, daya tahan tubuh, sehingga tua dengan mudah mendapatkan detak jantung cepat. Detak jantung berkaitan erat dengan penyakit kardiovaskuler. Pada lansia penerapan kegiatan lari kecil atau brisk walking ini mampu menurunkan denyut nadi dan tekanan darah pada lansia dengan hipertensi ringan. (Saraswati, 2019)

Latihan berjalan cepat adalah salah satu bentuk aerobik moderat senam latihan, untuk menentukan efek berjalan cepat latihan terhadap tekanan darah dari orang tua dengan hipertensi.(Berlian, 2019) Hal ini sejalan dengan hasil penelitian ini, responden mengalami penurunan tekanan darah sistolik dan diastolic sesudah dilakukan latihan.

\section{KESIMPULAN}

Kesimpulan penelitian ini terlihat dari frekuensi tekanan darah sebelum Brish Walking Exercise rata-rata 161,21 / 113,12 $\mathrm{mmHg}$. Frekuensi tekanan darah sesudah Brish Walking Exercise rata-rata pada 140,34 / 8,010 mmHg. Latihan Brisk Walking Exercise memiliki pengaruh terhadap perubahan tekanan darah yang terjadi pada lansia. Latihan Brish Walking Exercise ini diharapkan mampu menanganani lansia yang mengalami hipertensi, sehingga mampu mengurangi ketergantungan terhadap obat

\section{DAFTAR PUSTAKA}

Afriwardi (2009) Ilmu Kedokteran Olahraga. Jakarta: EGC.

Berlian, C. (2019) 'Pengaruh Brisk Walking Exercise Terhadap Tekanan Darah Pada Lanjut Usia Potensi Hipertensi Di Posyandu Lansia Kelurahan Rampal Celaket'. University of Muhammadiyah Malang.

DEPKES (2013) Riset Kesehatan Dasar. Available at: http://www.depkes.go.id/resources/dow nload/general/Hasil Riskesdas 2013.pdf (Accessed: 20 March 2018).

DEPKES (2016) Profil kesehatan jawa tengah. Available at: http://www.depkes.go.id/resources/dow nload/profil/PROFIL_KES_PROVINSI _2016/13_Jateng_2016.pdf.

Junaidi, I. (2010) Hipertensi (Pengenalan, 
Pencegahan, dan pengobatan). PT Bhuana Ilmu Populer.

Kronish, I. M. et al. (2014) 'Effect of peer education on stroke prevention: the prevent recurrence of all inner-city strokes through education randomized controlled trial', Stroke. Am Heart Assoc, 45(11), pp. 3330-3336.

Lipsky, M. et al. (2008) 'American Medical Association Guide to Preventing and Treating Heart Disease'. wiley.

Marlia (2010) Cegah hipertensi anak untuk generasi masa depan berkualitas. Jakarta: Salemba Medika.

Martono, H. (2011) Penatalaksanaan Hipertensi pada Usia Lanjut, Buku Ajar Geriatri (Ilmu Kesehatan Usia Lanjut) Edisi Ke-3. Jakarta: Balai Penerbit FKUI.

Miyashita, M., Burns, S. F. and Stensel, D. J. (2008) 'Accumulating short bouts of brisk walking reduces postprandial plasma triacylglycerol concentrations and resting blood pressure in healthy young men', The American journal of clinical nutrition. Oxford University Press, 88(5), pp. 1225-1231.

Niederhoffer KG, P. J. (2009) Berbagi cerita seseorang: Tentang manfaat menulis atau berbicara tentang pengalaman emosional. Edited by editor CR S, SJ L. Oxford University Press.

Notoadmojo, S. (2011) Metodologi penelitian kesehatan. Jakarta: Rineka Cipta.

Rofacky, H. F. and Aini, F. (2015) 'Pengaruh Terapi Spiritual Emotional Freedom Technique (SEFT) terhadap Tekanan Darah Penderita Hipertensi', Jurnal Keperawatan Soedirman, 10(1), pp. 4152.

S, D. (2011) Statistik Untuk Kedokteran dan Kesehatan. Jakarta: Salemba Medika.

Saraswati, R. U. (2019) 'Pengaruh Brisk Walking Exercise Terhadap Denyut Nadi Istirahat Pada Lansia Hipertensi Ringan Di Posyandu Lansia Rampal Celaket'. University of Muhammadiyah Malang.

Sonhaji, S. and Lekatompessy, R. (2019) 'Efektifitas Spiritual Emotional Freedom Technique (SEFT) dan menyanyi terhadap tekanan darah lansia di rumpelsos pucang gading semarang', Health Sciences and Pharmacy Journal, 3(1), pp. 14-20. 